\title{
CHANGES IN BONE MINERAL DENSITY AFTER TOTAL KNEE ARTHROPLASTY
}

\section{ALTERAÇÕES NA DENSIDADE MINERAL ÓSSEA APÓS ARTROPLASTIA TOTAL DO JOELHO}

\author{
Yasar Mahsut Dincel ${ }^{1}$ (i), abdulkadir Sari ${ }^{1}$ (i), Cagatay Tekin $^{1}$ (i), Burak Gunaydin ${ }^{1}$ (i), Mehmet Umit Cetin ${ }^{1}$ (i), \\ YUNUS ZIYA ARSLAN ${ }^{2}$ (1)
}

1. Namık Kemal University, Faculty of Medicine, Department of Orthopedics and Traumatology, Tekirdağ, Turkey.

2. Istanbul University-Cerrahpasa, Faculty of Engineering, Department of Mechanical Engineering, Istanbul, Turkey.

\section{ABSTRACT}

Objective: We aimed to investigate the change in bone mineral density (BMD) in the first postoperative year in patients that underwent total knee arthroplasty (TKA) due to primary osteoarthritis of the knee. Methods: Preoperative and first postoperative year dual-energy X-ray absorptiometry measurements of 76 patients with knee osteoarthritis, who undergone surgery between 2016 and 2018 due to the recommendation for TKA, were statistically evaluated in the study. Results: Of the 19 patients with a normal BMD in the preoperative period, $73.7 \%$ $(n=14)$ continued to have a normal BMD in the postoperative period. Of the 34 patients with a low BMD (osteopenia) in the preoperative period, $91.2 \%(n=31)$ did not show any change, whereas osteoporosis was observed in two patients (5.9\%) in the postoperative period. Of the 23 patients with osteoporosis in the preoperative period, $95.7 \%$ $(n=22)$ did not show any change, whereas osteopenia was observed in one patient (4.3\%) in the postoperative period. Both the $T$ and $Z$ scores of the spine (L1-L4) and proximal femur showed a slightly positive trend, however, with an insignificant statistical difference $(p \geq 0.05)$. Conclusion: Patients that underwent TKA experienced a statistically insignificant bone gain at the spine and proximal femur twelve months after the surgery. Level of Evidence III, Therapeutic Studies Investigating the Results of Treatment.

Keywords: Bone Density. X-Rays. Absorptiometry, Photon. Osteoarthritis, Knee. Osteoporosis. Arthroplasty, Replacement, Knee.

\section{RESUMO}

Objetivo: O objetivo foi investigar a alteração na densidade mineral óssea (DMO) no primeiro ano pós-operatório em pacientes submetidos à Artroplastia Total do Joelho (ATJ) por osteoartrite primária do joelho. Métodos: As medidas de absortiometria radiográfica com dupla energia no pré-operatório e no primeiro ano pós-operatório de 76 pacientes com osteoartrite do joelho, operados entre 2016 e 2018 devido à indicação de ATJ, foram avaliadas estatisticamente no estudo. Resultados: Dos 19 pacientes com DMO normal no pré-operatório, $73.7 \%(n=14)$ continuaram com DMO normal no pós-operatório. Dos 34 pacientes com baixa DMO (osteopenia) no pré-operatório, $91.2 \%$ ( $n=31)$ não apresentaram alteração, enquanto osteoporose foi observada em dois pacientes (5.9\%) no pós-operatório. Dos 23 pacientes com osteoporose no pré-operatório, 95.7\% ( $n=22)$ não apresentaram alteração, enquanto osteopenia foi observada em um paciente (4.3\%) no pós-operatório. Os escores Te Z da coluna vertebral (L1-L4) e do fêmur proximal mostraram uma tendência levemente positiva, mas a diferença foi estatisticamente insignificante ( $p \geq 0.05)$. Conclusão: Os pacientes submetidos à ATJ apresentaram um ganho ósseo estatisticamente insignificante na coluna vertebral e no fêmur proximal doze meses após a cirurgia. Nível de Evidência III, Estudos Terapêuticos - Investigação dos resultados do tratamento.

Descritores: Densidade Óssea. Raios X. Absorciometria de Fóton. Osteoartrite do Joelho. Osteoporose. Artroplastia do Joelho.

Citation: Dincel YM, Sari A, Tekin C, Gunaydin B, Cetin MU, Arslan YZ. Changes in bone mineral density after total knee arthroplasty. Acta Ortop Bras. [online]. 2020;28(5):247-250. Available from URL: http://www.scielo.br/aob.

\section{INTRODUCTION}

Total knee arthroplasty (TKA) is the most successful procedure in the treatment of osteoarthritis $(\mathrm{OA})$ in orthopedic surgery to control pain, improve functional quality, and enhance the quality of life. ${ }^{1}$ TKA surgery is usually performed when bone mineral density (BMD) starts to decrease due to normal aging. ${ }^{2}$

Several studies have aimed to specify the changes in the overall BMD of patients following TKA and researchers have reached different conclusions; some suggested an increase in BMD following TKA, ${ }^{3}$ others, in turn, argued that no changes were observed. ${ }^{4}$ It has also been suggested that there is a generalized loss of bone mineral density in the lower extremity after TKA as a result of immobilization and stress shielding effect of the femoral component. ${ }^{5}$ This incidence may increase the risk of fractures later in a population that may be already affected by osteoporosis (OP). ${ }^{6}$ Age-related OP, usually measured by BMD loss, is a known risk factor for fractures in older adults with significant negative consequences. ${ }^{6}$

All authors declare no potential conflict of interest related to this article.

The study was conducted at Namık Kemal University, Faculty of Medicine, Department of Orthopedics and Traumatology.

Correspondence: Yunus Ziya Arslan. Department of Mechanical Engineering, Faculty of Engineering, Istanbul University-Cerrahpasa. Makine Muhendisligi Bolumu, Istanbul UniversityCerrahpasa, Avcılar Istanbul, Turkey, 34320. yzarslan@istanbul.edu.tr 
The load distribution in the bone results in stress-adaptive bone remodeling (stress-protective effect) after TKA. ${ }^{7}$ This stress-protective effect is considered the primary determinant of BMD reduction in the early postoperative phase. Bone atrophy of up to $36 \%$ has been reported for the anterior aspect of the distal femur. ${ }^{8}$ The results of the periprosthetic BMD in the proximal tibia contradict each other. BMD had shown no change in some studies, ${ }^{9}$ whereas it either decreased ${ }^{10}$ or increased in others. ${ }^{11}$ It has been hypothesized that periprosthetic bone loss due to stress shielding may lead to the loosening of the implant and promote periprosthetic fractures. ${ }^{12}$ To our knowledge, although an empirically-represented negative relationship between BMD and fracture risk supports this theory, there is no evidence for this correlation.

Since there is no consensus on the change in the BMD of patients following TKA, we aimed to investigate the change in BMD in the first postoperative year in patients that underwent unilateral TKA due to Kellgren-Lawrence Stage 4 primary OA of the knee.

\section{MATERIALS AND METHODS}

This is a retrospective study including only information from the patients' files and hence no written consent from the patients was considered necessary.

A total of 76 patients (70 women, 6 men) that underwent TKA due to the diagnosis of advanced stage primary gonarthrosis between November 2016 and February 2018 were included in our study. Ethical committee approval numbered 1111 and dated 05.17.2018 was obtained from the Local Ethics Committee of Clinical Studies at the Department of Orthopedics and Traumatology, Faculty of Medicine, Namık Kemal University.

Patients with secondary gonarthrosis due to rheumatologic, traumatic or septic reasons and patients with a history of knee, hip or ankle surgery were excluded. Patients' age, records of previous knee surgery and the age of menopause were recorded on the FRAX (Fracture Risk Assessment Tool) table. The patients had a mean age of $65.67 \pm 7.70$ (range: 51 to 84 ) years. Their body mass index (BMI) ranged between 26.29 and 47.26 , with a mean of 36.55 . The females suffering from menopause had a mean age of 45.38 (range: 30 to 56) years. There were no differences in the descriptive characteristics (age, height, weight) of the patients.

The patients were operated on using the same brand prosthesis (Zimmer-Nexgen ${ }^{\circledR}$; Zimmer Biomet, Warsaw, IN, USA) by four surgeons in our clinic with sequential randomization. All patients got the same rehabilitation program after the surgery. Dual-energy X-ray absorptiometry (DXA) control was added to the preoperative and first postoperative year follow-up assessments.

DXA scan quantitatively analyzes the local metabolic activity of bone tissue, being considered a valuable tool to evaluate the integration between bone and prosthetic components, allowing for early detection of any changes between prosthesis and bone interface in TKA and for following up on the remodeling of the bone between the bone and the prosthetic interface. ${ }^{13}$

Preoperative and postoperative DXA measurements of the patients were performed at the spine (between L1 and L4) and proximal femur (femoral neck). The Horizon DXA System (Hologic Inc., Marlborough, MA, USA) was used in the DXA measurements of the patients and conducted at the Physical Therapy and Rehabilitation Department of the Faculty of Medicine of Namık Kemal University.

\section{Statistical evaluation}

The preoperative and first postoperative year DXA measurements of the patients were statistically evaluated. The SPSS v. 25 software (SPSS Inc., Chicago, IL, USA) was used in the statistical analysis. The normality of the data was analyzed using the KolmogorovSmirnov test. The paired-sample t-test was used to compare the differences between two pairs in intergroup comparisons and the chi-square analysis was used to compare the categorical variables. A $p$ value of less than 0.05 was considered statistically significant.

\section{RESULTS}

Of the 19 patients with a normal BMD in the preoperative period, $14(73.7 \%)$ continued with a normal BMD in the postoperative period (Table 1).

Table 1. Postoperative changes of the patients with normal bone mineral density in the preoperative course $(n=19)$.

\begin{tabular}{c|c|c|c}
\hline & $\begin{array}{c}\text { Postoperative } \\
\text { normal }\end{array}$ & $\begin{array}{c}\text { Postoperative } \\
\text { osteopenic }\end{array}$ & $\begin{array}{c}\text { Postoperative } \\
\text { osteoporotic }\end{array}$ \\
\hline Number of patients & 14 & 4 & 1 \\
\hline Percentage of patients (\%) & 73.7 & 21.1 & 5.3 \\
\hline
\end{tabular}

Of the 34 patients with a low BMD (osteopenia) in the preoperative period, 31 (91.2\%) did not show any change, whereas osteoporosis was observed in two patients (5.9\%) in the postoperative period (Table 2).

Table 2. Postoperative changes of the patients with osteopenia in the preoperative course $(n=34)$.

\begin{tabular}{c|c|c|c}
\hline & $\begin{array}{c}\text { Postoperative } \\
\text { normal }\end{array}$ & $\begin{array}{c}\text { Postoperative } \\
\text { osteopenic }\end{array}$ & $\begin{array}{c}\text { Postoperative } \\
\text { osteoporotic }\end{array}$ \\
\hline Number of patients & 1 & 31 & 2 \\
\hline Percentage of patients (\%) & 2.9 & 91.2 & 5.9 \\
\hline
\end{tabular}

Of the 23 patients with osteoporosis in the preoperative period, $22(95.7 \%)$ did not show any change, whereas osteopenia was observed in one patient (4.3\%) in the postoperative period (Table 3).

Table 3. Postoperative changes of the patients with osteoporosis in the preoperative course $(n=23)$.

\begin{tabular}{c|c|c|c}
\hline & $\begin{array}{c}\text { Postoperative } \\
\text { normal }\end{array}$ & $\begin{array}{c}\text { Postoperative } \\
\text { osteopenic }\end{array}$ & $\begin{array}{c}\text { Postoperative } \\
\text { osteoporotic }\end{array}$ \\
\hline Number of patients & 0 & 1 & 22 \\
\hline Percentage of patients (\%) & 0 & 4.3 & 95.7 \\
\hline
\end{tabular}

Although both the $T$ and $Z$ scores of the spine showed a mild positive trend, the difference between the pre- and postoperative periods was statistically insignificant $(p \geq 0.05)$ (Table 4$)$.

Table 4. Postoperative changes in the $T$ and $Z$ scores of the $L 1-L 4$ section and Ward's area.

\begin{tabular}{c|c|c}
\hline & Preoperative & Postoperative \\
\hline T score & -0.6934 & -0.6763 \\
\hline Z score & 0.9816 & 0.9947 \\
\hline
\end{tabular}

The $T$ and $Z$ scores of the proximal femur similarly showed a slightly positive trend in the postoperative course, but the change was statistically insignificant ( $p \geq 0.05$ ) (Table 5).

Table 5. Postoperative changes in the $T$ and $Z$ scores of the proximal femur.

\begin{tabular}{c|c|c}
\hline & Preoperative & Postoperative \\
\hline T score & -1.5763 & -1.5513 \\
\hline Z score & -0.0461 & -0.0632 \\
\hline
\end{tabular}

\section{DISCUSSION}

Since there is no consensus on the change in BMD in patients following TKA, ${ }^{3,4}$ we aimed to comparatively investigate the 
preoperative and first postoperative year bone mineral densities in our study. Although we observed a slightly positive BMD trend in the spine and proximal femur, we could not find statistically significant different $T$ and $Z$ scores between the preoperative and first postoperative periods.

To date, no positive correlation has been established between OP and $O A .{ }^{14}$ Whereas the accepted risk factors for OP are old age and a low BMD, the accepted risk factors for OA are old age and high BMI. ${ }^{15}$ However, both diseases can be seen concomitantly related to patient's age, body weight, and living conditions such as long-term inactivity. ${ }^{15}$ The mean femoral BMD in the proximal femur with a low stage knee OA was 5-9\% higher compared to those without knee OA. ${ }^{15}$ It was reported that the mean BMD of the femur in patients in the final stage of OA was not higher than those without $\mathrm{OA} .{ }^{15}$ In other study that investigated the BMD of both hips in advanced stage OA patients, Lingard et al. ${ }^{16}$ reported that the BMD of the hip on the side of the symptomatic knee was lower and it showed a positive correlation with the degree of the radiographic change and a negative correlation with the knee functionality. ${ }^{16}$ The authors investigated the prevalence of $\mathrm{OP}$ in patients with severe hip and knee OA subjected to joint arthroplasty and reported that $23 \%$ and $43 \%$ of the overall rate of OP was classified as osteopenia. In our study, of the patients with preoperative advanced OA, 34 (44.7\%) were diagnosed with osteopenia and 23 (30.2\%) with OP. The prevalence of OP in our study was similar to that in a study by Lingard et al. ${ }^{16}$

The L1-L4 section and Ward's area (total section) are valuable as the BMD measurements performed in the axial skeleton and outside the implantation site. Compression fractures in senile osteoporosis of the lumbar region are common. We did not find this type of fracture in our study (Table 4). Due to the BMD measurements in the proximal femur, the trochanteric region was predominantly evaluated and no changes that would affect the results were observed (Table 5). We did not find any fractures in the proximal femur, which is a common site of fracture in senile osteoporosis.

Considering all the results of our study, although it is not statistically significant, we can understand that the course of a patient with a normal BMD may turn to osteopenic and even osteoporotic, whereas it is harder to state the otherwise. Only one of the osteopenic patients returned to normal (Table 2). Likewise, only one of the osteoporotic patients returned to an osteopenic course (Table 3). On the other hand, of five patients found to be normal in the preoperative measurement, four became osteopenic and one osteoporotic, postoperatively (Table 1). Two patients with preoperative osteopenic findings became osteoporotic postoperatively (Table 2).

Most of the studies evaluating the BMD changes after TKA have focused on measuring the BMD changes in the periprosthetic region. Ishii et al. ${ }^{3}$ studied the BMD changes in the bilateral hips of 24 patients (4 men, 20 women; mean age: 69 [range: 60 to 83] years) with TKA. Despite the decrease in the total BMD of the hip found in the first six months, the authors concluded that the BMD reached the basal level by the postoperative second year and that TKA prevented BMD loss due to increased postoperative mobility. Van Loon et al. ${ }^{4}$ measured the BMD change in the bilateral hips and spine in 12 patients after TKA and reported that the BMD measurements at the $12^{\text {th }}$ postoperative month were similar to the preoperative measurements. Soininvaara et al. ${ }^{6}$ measured the bilateral hip BMD in 69 patients ( 20 men, 49 women; mean age: $67 \pm 6.8$ years) that had undergone TKA and detected a change in BMD at the ipsilateral hips up to $-2.7 \%$ and a change at the contralateral hips up to $-1.18 \%$ at the first postoperative year. The BMD reduction observed in all these studies was within the range of the expected age-related BMD changes. However, none of these studies showed compliance with differences in age and sex due to the limited sample size, and compared their results according to the normative data adjusted to age and sex published on the expected changes in BMD.

The duration of the follow-up period of patients that underwent TKA for the changes in BMD measurements has been a matter of debate. In our study, we preferred a one-year follow-up period, since the average duration of follow-up in the previous studies varied between 6 and 24 months. Despite the slight decrease in BMD after 12 months, an insignificant difference was reported after a follow-up period of 12 to 24 months. ${ }^{17}$

In our study, the patients were not given the preoperative treatment, since we aimed to observe the change in BMD after TKA application. This issue has been widely studied in the literature. In a study by Jiang et al., ${ }^{18}$ treatment with bisphosphonates was initiated with surgery and regional BMD reductions were detected during the $3^{\text {rd }}$ or $6^{\text {th }}$ month measurements. The BMD levels at the $12^{\text {th }}$ and $24^{\text {th }}$ months follow-ups were either the same as or higher than the preoperative period measurements. On the other hand, the BMD levels of the untreated group were low at the $24^{\text {th }}$ month follow-up. It was asserted that bisphosphonate therapy may prevent aseptic loosening before joint replacement surgery and would reduce the fractures of cancellous bone formed during the postoperative period..$^{19}$

In our study, the BMD measurements of the spine and proximal femur localization showed no significant difference. In a study by Beaupre et al., ${ }^{20}$ the first postoperative year BMD values of both the hips and the spine showed a negative change compared to the preoperative period. In some other studies, the BMD change in the hip at the operated side was significantly higher than the other parts of the body. ${ }^{20}$ In our study, both the T and Z scores of the spine and proximal femur measured in the postoperative course showed a mild positive trend compared to those in the preoperative period ( $p \geq 0.05$ ).

The limitations of our study are the lack of BMD measurements at the third, sixth and ninth postoperative months and the lack of evaluation of the BMD changes in the knee, although the orthoroentgenograms of the patients were taken. We measured the BMD in the first postoperative year so we could not interpret the trajectory of bone loss or the long-term effects of TKA on $\mathrm{BMD}$. Moreover, few patients had a history of antiaggregant use that could negatively affect the bone structure. However, this drug interaction was not investigated, since it would not cause a statistically significant change in the results of the group of patients included in our study. Although the femoral neck and intertrochanteric region have been measured separately in BMD measurement of the hip region in several publications, the fact that no such distinction was made by us and the incapability of the device used in our study was another limiting aspect. In addition, since our study was designed to evaluate the effect of knee arthroplasty on BMD, postponing the treatment of the osteoporotic patient for a period of one year is another limitation for our study.

\section{CONCLUSION}

The subjects that underwent primary cemented TKA experienced a statistically insignificant bone gain at the spine and proximal femur within the first postoperative year. Future studies with long-lasting and more frequent follow-ups are needed to understand the impact of post-fracture changes in BMD on fracture risk. 
AUTHORS' CONTRIBUTIONS: Each author contributed individually and significantly to the development of this article. YMD: conceptualization and data analysis; AS: data analysis, study supervision and article review; CT: conceptualization, data analysis and article review; BG: conceptualization, data analysis and article review; MUC: conceptualization and article review; YZA: statistical analysis, study supervision and article review.

\section{REFERENCES}

1. Innocenti M, Matassi F, Carulli C, Nistri L, Civinini R. Oxidized zirconium femora component for TKA: a follow-up note of a previous report at a minimum of 10 years. Knee. 2014;21(4):858-61.

2. Warming L, Hassager $C$, Christiansen $C$. Changes in bone mineral density with age in men and women: a longitudinal study. Osteoporos Int. 2002;13(2):105-12.

3. Ishii $Y$, Yagisawa K, Ikezawa $Y$. Changes in bone mineral density of the proximal femur after total knee arthroplasty. J Arthroplasty. 2000;15(4):519-22.

4. van Loon CJ, Oyen WJ, Waal Malefijt MC, Verdonschot N. Distal femoral bone mineral density after total knee arthroplasty: a comparison with general bone mineral density. Arch Orthop Trauma Surg. 2001;121(5):282-5.

5. Levitz CL, Lotke PA, Karp JS. Long-term changes in bone mineral density following total knee replacement. Clin Orthop Relat Res. 1995;(321):68-72.

6. Soininvaara TA, Miettinen HJ, Jurvelin JS, Alhava EM, Kröger HP. Bone mineral density in the proximal femur and contralateral knee after total knee arthroplasty. J Clin Densitom. 2004;7(4):424-31.

7. Saari T, Uvehammer J, Carlsson LV, Regnér L, Kärrholm J. Posterior stabilized component increased femoral bone loss after total knee replacement: 5-year follow-up of 47 knees using dual energy X-ray absorptiometry. Knee. 2006;13(6):435-9

8. Minoda Y, Kobayashi A, Iwaki H, Ikebuchi M, Inori F, Takaoka K. Comparison of bone mineral density between porous tantalum and cemented tibial total knee arthroplasty components. J Bone Joint Surg Am. 2010;92(3):700-6.

9. Petersen MM, Gehrchen PM, Ostgaard SE, Nielsen PK, Lund B. Effect of hydroxyapatite-coated tibial components on changes in bone mineral density of the proximal tibia after uncemented total knee arthroplasty: a prospective randomized study using dual-energy $\mathrm{x}$-ray absorptiometry. J Arthroplasty. 2005;20(4):516-20.

10. Chen SH, Chiang MC, Hung CH, Lin SC, Chang HW. Finite element comparison of retrograde intramedullary nailing and locking plate fixation with/without an intramedullary allograft for distal femur fracture following total knee arthroplasty. Knee. 2014;21(1):224-31.

11. McClung MR. The relationship between bone mineral density and fracture risk. Curr Osteoporos Rep. 2005;3(2):57-63.

12. Cummings SR, Melton LJ. Epidemiology and outcomes of osteoporotic fractures. Lancet. 2002;359(9319):1761-7.

13. Piscitelli $P$, Iolascon $G$, Innocenti $M$, Civinini R, Rubinacci $A$, Muratore $M$, et al. Painful prosthesis: approaching the patient with persistent pain following tota hip and knee arthroplasty. Clin Cases Miner Bone Metab. 2013;10(2):97-110.

14. Foss MV, Byers PD. Bone density, osteoarthritis of the hip, and fracture of the upper end of the femur. Ann Rheum Dis. 1972;31(4):259-64.

15. Mont MA, Gwam C, Newman JM, Chughtai M, Khlopas A, Ramkumar PN, et al. Outcomes of a newer-generation cementless total knee arthroplasty design in patients less than 50 years of age. Ann Transl Med. 2017;5(Suppl 3):S24.

16. Lingard EA, Mitchell SY, Francis RM, Rawlings D, Peaston R, Birrell FN, et al. The prevalence of osteoporosis in patients with severe hip and knee osteoarthritis awaiting joint arthroplasty. Age Ageing. 2010;39(2):234-9.

17. Dobbs MB, Buckwalter J, Saltzman C. Osteoporosis: the increasing role of the orthopaedist. lowa Orthop J. 1999;19:43-52.

18. Jiang G, Kang L, Wang H, Zhang J. The influence of bisphosphonate on bone mineral density after total knee arthroplasty: a randomised controlled trial. Int J Surg Open. 2017;7:17-21.

19. Aspenberg P. Bisphosphonates and implants: an overview. Acta Orthop 2009;80(1):119-23.

20. Beaupre LA, Rezansoff A, Clark M, Jen H, Lambert RG, Majumdar S. Bone mineral density changes in the hip and spine of men and women 1-year after primary cemented total knee arthroplasty: prospective cohort study. J Arthroplasty. 2015;30(12):2185-9. 